\title{
Chikungunya in Children: A Study Conducted in Hospitalised Patients During 2016 Epidemic in Delhi
}

\author{
Neeru Gupta*, Chhaya Gupta, Jatin Munjal, Shephali sharma and Hema Rani
}

Sri Balaji Action Medical Institute, Paschim vihar, New Delhi, India

\begin{abstract}
Chikungunya fever is caused by Chikungunya virus (CHIKV)and spread by Aedes aegypti and Aedes albopictus.Clinical manifestations of chikungunya fever are variable and ranges from abrupt onset fever, skin rashes, minor haemorrhages ,arthralgia/arthritis, vomiting, diarrhoea to severe manifestations like encephalitis, optic neuritis, seizures, retrobulbar neuritis and acute flaccid paralysis however some clinical features are different in children and adults. This study was carried out to characterise the epidemiological, clinical, radiological and laboratory parameters along with outcomes in all cases of chikungunya positive hospitalised children during 2016 epidemic of chikungunya in Delhi from august to november 2016.
\end{abstract}

\section{Keywords: Chikungunya Fever,Children,Epidemic,Fever}

\section{Introduction}

Chikungunya is a viral disease caused by the alphavirus that is transmitted to humans by bite of infected Aedes aegypti mosquitoes. The name is derived from the Makonde word meaning "that which bends up" in reference to the stooped, posture developed as a result of the arthritic symptoms of the disease ${ }^{1,2}$ Chikungunya virus[CHIKV] was first isolated from the serum of a human in Tanzania in $1952^{3}$. In India CHIKV was first reported in 1963 in Calcutta. 4,5 The disease re-emerged in India in October 2006 after remaining silent for nearly 32 years. ${ }^{6}$ An estimated 1.38 million people across southern and central India developed symptomatic disease. ${ }^{6,7}$ No deaths directly attributable to this disease were reported in 2006 Indian epidemic. ${ }^{8}$ During 2015 , a total27,553 clinically suspected cases of chikungunya have been reported from 22 states and 3 union territories(UT). Currently in 2016, till $11^{\text {th }}$ September 2016 a total of 14656 clinically suspected cases (including 1724 in Delhi) from 18 states and 2 UT's have been reported. ${ }^{9}$ Clinical manifestations of chikungunyafever are variable ranging from the asymptomatic illness to a severe deliberating disease. Children are among the group at maximum risk for severe manifestations of the disease and some clinical features in this group are distinct a from those seen in adults. ${ }^{10}$ This study was carried out to characterize the epidemiological, clinical ,biological and radiological features and outcomes of all the cases of chikungunya fever among children admitted to the tertiary care hospital during 2016 outreak.

\section{Material and Methods}

This was retrospective and prospective study involving children over a period of 4 months (from august to november) 2016. Children who had chikungunya signs and symptoms with established diagnosis by reverse transcriptase PCR used for viral RNA detection were only considered for the study. All the clinical parameters, laboratory investigations, radiological findings and outcome were assessed and recorded.

\section{Results}

We studied 85 cases of chikungunya detected positive by RT-PCR, over a period of 4 months(august to november 2016) . Out of these 85 cases, 58 (68.2\%) were males and 27 (31.8\%) were females.(Figure 1)Majority of cases were noted in the age group of $12-18$ years $(38.8 \%)$ followed by the 5-11 years age group(34.1) (Figure 2)

All patients $(100 \%)$ presented with fever. The other prominent presenting symptoms were bodyache $(28.2 \%)$, joint pain (14.1\%) and rash (14.1\%), Generalised weakness was reported by 5 patients $(5.9 \%)$. Bleeding manifestations were observed in the form of malaena $(2.4 \%)$ and nasal bleeding (2.4\%). The other presenting complaints included chills $(7.1 \%)$ and vomiting (2.4\%). On examination $3.5 \%$ patients were found to have petechial rash with flushing and urticaria. (Figure 3)

Upon investigating, $41.2 \%$ patients were found to have low haemoglobin and $44.7 \%$ patients had thrombocytopenia. Derangement of liver enzymes was noted in $17.6 \%$ of children. Abnormalities in the coagulation studies were observed in $10.6 \%$ of children, with raised prothombin time in $10.6 \%$ and activated partial thromboplastin time in $5.9 \%$. cases. Ultasonographic examination of whole abdomen was carried out in 16 patients, of which 10 patients had a normal study while in other 7 patients significant findings 
were observed. These findings included hepatomegaly in 2 patients, free fluid in pelvis in 1 patient, mesenteric lymphadenopathy in 1 patient and pericholecystic fluid collection in 1 patient. Chest X-Ray examination was done in 7 patients, of these 1 patient had consolidation and 1 patient showed features of resolving pneumonitis and pleural effusion.(Table1)
In the current study $10(11.7 \%)$ out of 85 cases developed complications. These included seizures in 6 cases, 1 case of encephalopathy with disseminated intravascular coagulation and acute renal injury and optic neuritis in 1 of the patient. 10 patients required transfusion for deranged coagulation profile and one patient required mechanical ventilation for respiratory distress.

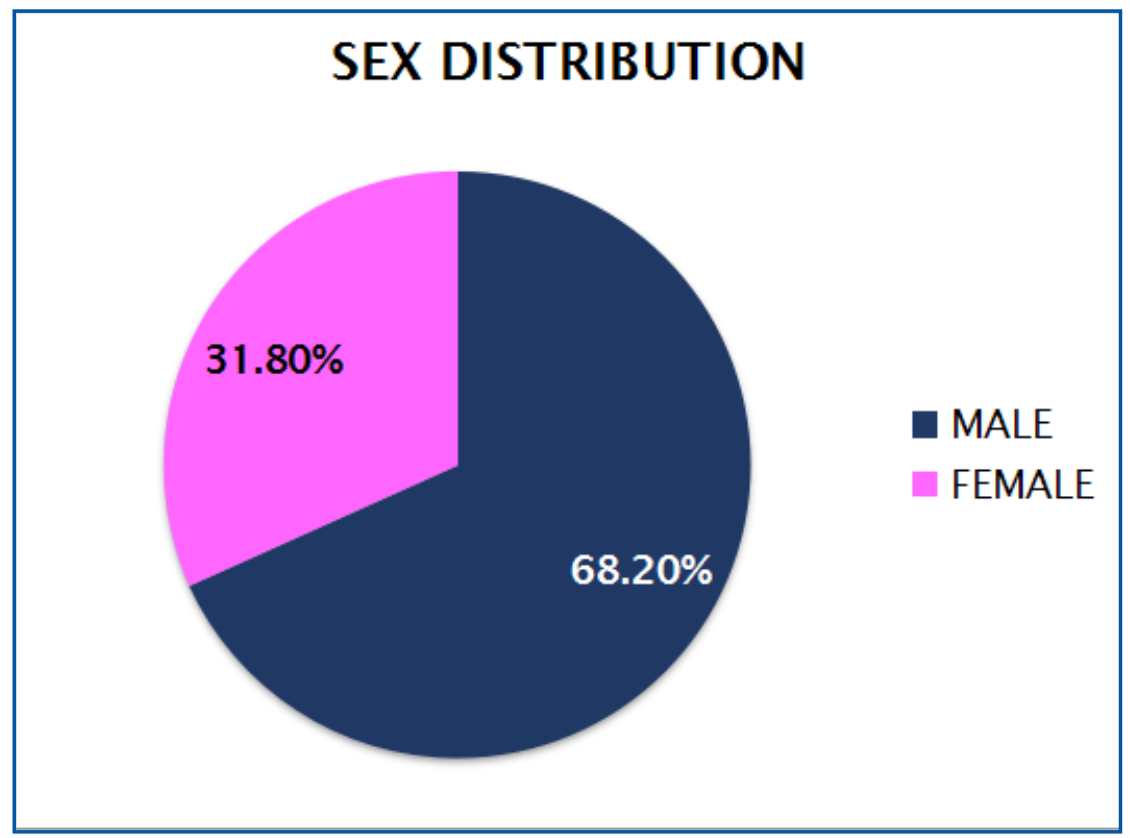

Fig. 1: Male Female Distribution.

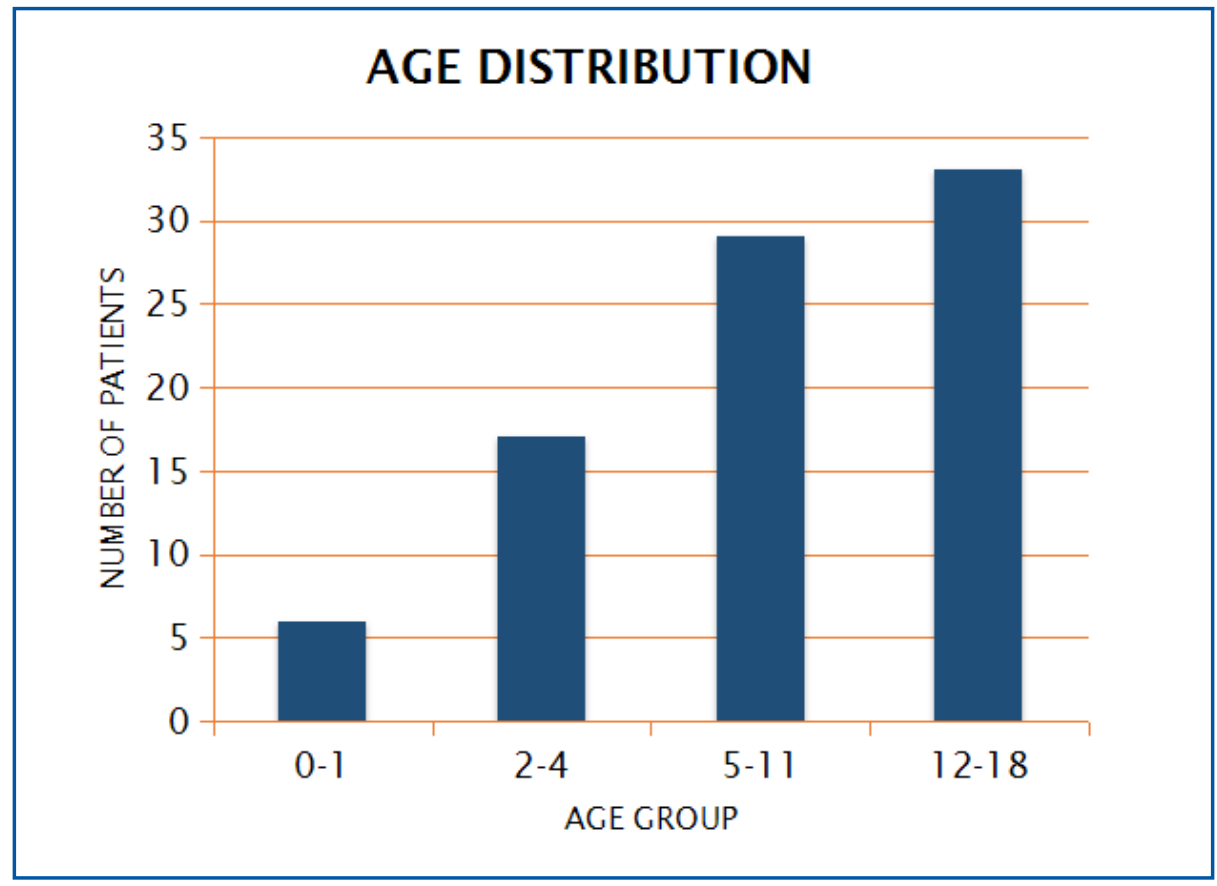

Fig. 2: Age Distribution. 


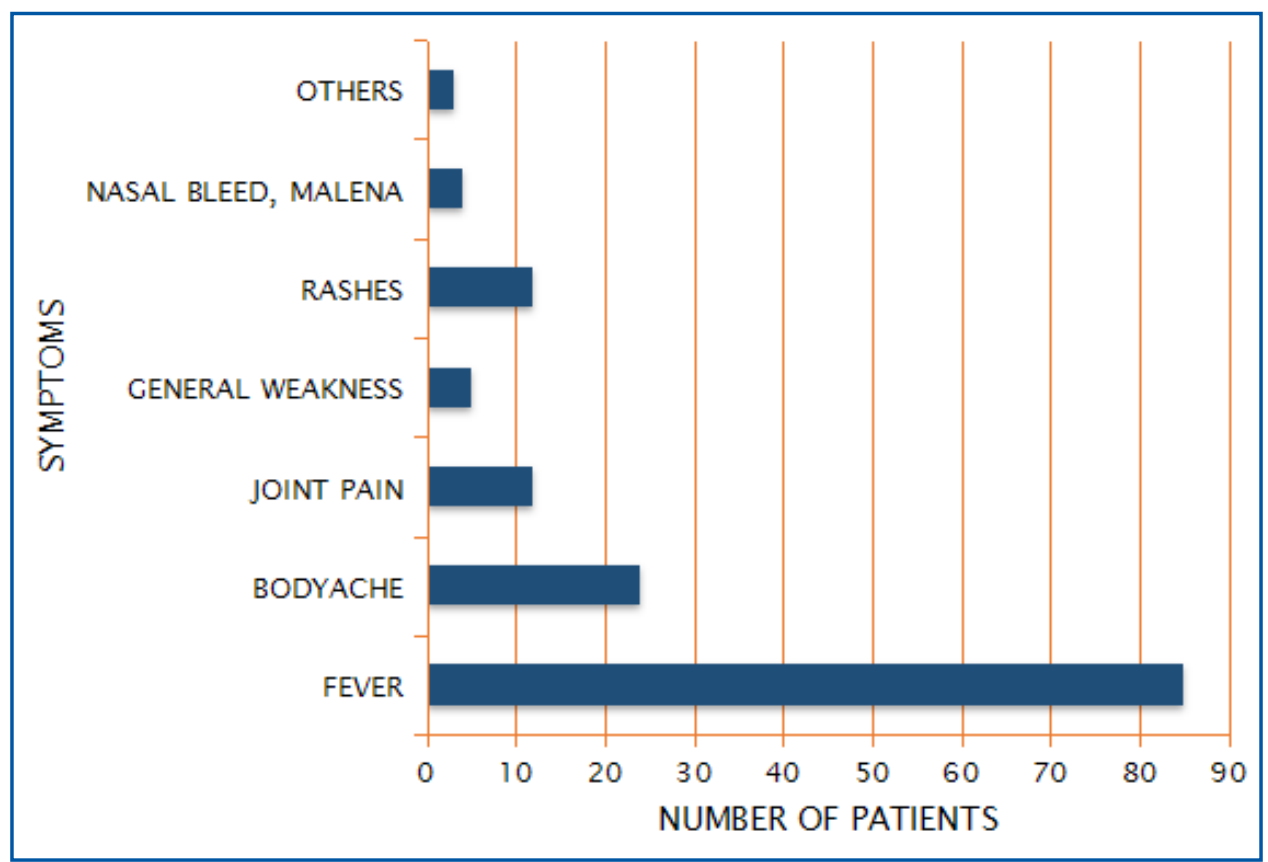

Fig. 3: Clinical Features in Chikungunya Patients..

Table 1: Laboratory Investigations, Radiological Findings and Complications in Chikungunya Patients.

\begin{tabular}{|c|c|c|}
\hline INVESTIGATIONS & CASES & PERCENTAGE \\
\hline Low Hemoglobin & 35 & 41.2 \\
\hline Low Platelet Count & 38 & 44.7 \\
\hline Derranged Liver Function & 15 & 17.6 \\
\hline Derrnged Coagulation Profile & 9 & 10.6 \\
\hline Rapid Malarial Parasite Test (P.Vivax) & 1 & 1.2 \\
\hline \multicolumn{3}{|c|}{ Radiological Findings } \\
\hline CHEST X- RAY (N=7) & 3 & 42.9 \\
\hline USG ABDOMEN (N=16) & 6 & 37.5 \\
\hline \multicolumn{3}{|c|}{ Complications } \\
\hline Seizures & 6 & 7.1 \\
\hline Optic Neuritis & 1 & 1.2 \\
\hline Encephalopathy With D.I.C. & 1 & 1.2 \\
\hline Transfusion & 10 & 11.8 \\
\hline Mechanical Ventilation & 1 & 1.2 \\
\hline
\end{tabular}

\section{Discussion}

The chikungunya epidemic epitomizes the classic interaction between agent, host and environment. The reasons for the re-emergence of chikungunya in the Indian subcontinent are unclear. The plausible explanations include increased tourism, chikungunya virus isolation into a new population and viral mutation.

The common clinical manifestations of chikungunya in children include sudden onset high grade fever, maculopapular rash, pigmentary changes, bullous rash / skin blistering in infants of less than six months of age, myalgia, arthralgia, seizures, acute encephalopathy, meningoencephalitis, severe nasal bleeding, headache and purpura with $35-40 \%$ asymptomatic cases. ${ }^{11}$

Study by Swarrop et a ${ }^{12}$ and Valamparampil et at ${ }^{13}$ reported sudden onset fever with chills and rigors which subsided in $2-3$ days. In our study we also encountered similar results along with associated constitutional symptoms like 
bodyache and generalized weakness. Rash was observed in children suffering from chikungunya in our study and similar results were also noted in the Afzal et at ${ }^{14}$ and Thiberville et al ${ }^{15}$ studies. WHO guidelines on clinical management of chikungunya fever ${ }^{16}$ states about rarity of symptoms of vomiting, diarrhea and photophobia. Similar findings were also detected by us with presence of these symptoms in 2 out of 85 patients only. In our study the investigations revealed thrombocytopenia 38(85), anaemia $35(85)$ and deranged liver function tests $9(85)$ similar to study by Afzal et al in which thrombocytopenia was commonly encountered however Mangalgi et at ${ }^{17}$ reported less frequent thrombocytopenia and hyperbilirubinemia in their study. Joint specific arthralgia is a well characterized hallmark of chikungunya during the acute phase of disease ${ }^{18}$. Simarmata et al ${ }^{19}$ encountered joint pain in 14(56) patients. Only 2 of 11 infants and 9 of 22 children developed joint symptoms in series of cases studied in Vellore ${ }^{20}$. In our study we recorded joint pains in 12 of 85 children. Chew et $\mathrm{al}^{21}$ reported deranged coagulation profile in chikungunya outbreak in Malaysia in 2008. In our study 9 out of 85 evaluated patient had deranged coagulation parameters. The rare complications comprising of encephalitis, seizures and optic, neuritis observed in this study were also reported in studies by Taraphdar et al ${ }^{22}$, Robin et al ${ }^{23}$, Chusri et al ${ }^{24}$, Martin et al ${ }^{25}$, Lewthwaite et $\mathrm{al}^{26}$, and Mittal et al. In our study severe form of chikungunya requiring transfusion of components due to deranged coagulation profile and mechanical ventilation to manage respiratory distress were observed. The children manifesting the chikungunya complications also required hospitalization in the intensive care unit in our study. The similar intensive care unit admissions were also required in the study by Pellot et al 27. In our study, 4 cases of chikungunya positive patients tested positive for dengue IgM similar to Shruti et al ${ }^{28}$. This can be attributed to either co - infection or dual infection. In Asia chikungunya affected areas overlap with dengue epidemic areas and provide opportunities for the mosquitoes to become co- infected with both the viruses resulting in significant co - infection.

\section{Conclusion}

Chikungunya fever is self limiting and presents different spectrum of disease in infants compared to older children and adults. It should be one of the close differential diagnosis in children presenting with non specific features of fever along with joint pains and rash especially in Asian continent where prevelance of this arthropod borne disease is quite high. The availability of reliable and affordable diagnostic tests would improve the patient management and contribute towards the accurate assessment of the disease.

\section{References}

1. Ravi V. Re-emergence of chikungunya virus in India. Indian J Med Microbial 2006, 24:83-84

2. Chhabra M. Mittal V, Bhattacharya D, RanaUVS, Lal S. Chikungunya fever : A re-emerging viral infection. India J Med Microbial 2008; 26: 5-12.

3. Karthikyan M, Deepa K.M. A study on chikungunya cases in Palakkad, India. Acta Medica Medianae 2011, 50 (1) : $17-20$.

4. Chattopadhyay S, Mukherjee R, Nandi A, Bhattacharya N. Chikungunya virus infection in west Bengal, India. Indian J Med Microbiol 2016; 34:213 -215.

5. Patil SS, Patil RS, Durgawale PM, Patil AG. A stydy of the outbreak of chikungunya fever. J Clin Diagn Res 2013; 7(6): $1059-1062$

6. Kalantri SP, Joshi R, Riley LW. Chikungunya epidemic: An Indian perspective. The National Med J India 2006; $19: 315-22$

7. Suryawanshi SD, Dube A H, Khadse Reveal K, Jalgaonkar S V, Sathe P S, Zawar S D, Holay MP. Clinical profile of chikungunya fever in patients in a tertiary care centre in Maharahtra, India. Indian J Med Res 2009; 129: 438 - 441.

8. Mavalankar D, Shastri P, Bandyopadhyay T, Parmar J, Ramani K V. Increased mortality rate associated with chikungunya epidemic, Ahmedabad, India. Emerging infec Dis 2008; 14(3): $412-415$.

9. Bhatnagar P K, Garg S K, Bano T, Jain S. knowledge, attitude and practice regarding Dengue and Chikungunya in secondary school children in a city of north india Eurp J PharmMed Res 2016; 3(11): 423 - 428.

10. Sebastian MR, Lodha R, Kabra SK. Chikungunya infection in Children. Indian J Pediatr 2009; 76:185.

11. Nicole R, Markus H, Patrick G. Chikungunya in children. The Ped Inf Dis J 2015; 34(7): 789 - 791

12. Swaroop A, Jain A, Kumhar M, Parihar N, Jain S. Chikungunya fever. JIACM 2007; 8: $164-168$.

13. Valanparampil J, Chirakkarot S, Letha S, Jayakumar C, Gopinathan KM. Clinical profile of chikungunya in infants. Ind J Ped 2009; 76: 151 - 155.

14. Afzal MF,Naqvi SQ,Sultan MA,HanifA. Chikungunya fever among children presenting with non specific febrile illness during an epidemic of dengue fever in Lahore,Pakistan. Merit Res J Med Sci 2015;3(3):069-073

15. Thiberville SD, Boisson V, Gaudart J,Simon F, Flahault A. Chikungunya fever: A clinical and virological investigation of outpatients of Reunion Island south- west Indian ocean. PLoS Negl Tro Dis 2004.ashyj, 7:e

16. Guidelines on clinical management of chikungunya fever by WHO,oct 2008. http:// www.wpro.who.int/mVp/topics/ntd/ clinical management assessed on 9 December 2016.

17. Mangalgi SM, shenoy S, Maralusiddappa PG, Aprameya IV. Neonatal chikungunya - A case series J.Ped Sci 2011; $3(2)$ : e 74 . 
18. Teng TS, Kam YW, Lee B, Hapuarachchi HC, Wimal A, NG LC, Ng LF. A systematic meta - analysis of immune signatures in patients with acute chikungunya virus infection. J. infect dises 2015; 211: 1925 - 1935.

19. Simarmata D, Ng DCE, Kam YW, Lee B, Sum MSH, Her $\mathrm{Z}$, chow A et al. Early clearance of chikungunya virus in children is associated with a strong innate immune response. Sci Rep 2016; 6, 26097.

20. Malik S, Mehta KD, Singh KP, Dhole TN. Emergence of chikungunya infection in North India. Arch pathol lab Med 2016 (12); 3(4): 314 - 319.

21. Chew LP, Chua HH. Outbreak of chikungunya in Johar Bahru, Malaysia. Clinical and laboratory features of hospitalised patients. Med J Malaysia 2009; 64(3): 220 - 222.

22. Taraphdar D, Roy BK, Chatterjee S. Chikungunya virus infection amongst the acute encephalites symdrome cases in West Bengal, India. Indian J Medical Microbiol 2015; 33, Supple S1: 153 - 6

23. S Robin, Ramful D, Jaffar - Bandijee MC, Rigou G, Alessandri JL, Neurologic manifestations of pediatric chikungunya infection, J child neurol 2008 (7); 23(9): $1028-1035$.

24. Chusri S, Siripceitoon P, Hirunpat S, Silpapojakul V. Case reports of neuro chikungunya in Southern Thailand. Am J Trop Med Hyg. 2011(8); 85(2): 386 - 9

25. Martins HA del, Bernardino SN, Santos CC, Ribas VR, Valenca MM. Neuro - Chikungunya : a review. Med Res. Arch 2016(9); 4(5): 1-12

26. L Penny, V Rair, Osbome JC, Begum A, Platnk JLM, Shankar MV, Hewson Roger et al. Chikungunya virus and central nervous system infections in children, India. Emergence infect Dis 2009 (2); 15(2): 329 - 331

27. Mittal A, Mittal S, Bharati MJ, Ramakrishnan R, Sarwanan S, Sathe PS. Optic neuritis associated with chikungunya virus infection in South India. Arch ophthalmol 2007, oct; 125 (10) : $1381-6$

28. Malik S, Mehta KD, Singh KP, Dhole TN. Emergence of chikungunya infection in North India. 2016, oct - Dec: 3(4) : 314 - 319.

*Corresponding author:

Dr.Neeru Gupta, BN-41, East Shalimar Bagh, Delhi. 110088

Phone: +919871603553

Email: drguptaneeru@gmail.com

Financial or other Competing Interests: None. 